\title{
Comparison of EPS Geofoam and Stone columns in heave reduction of expansive soils
}

\author{
Thentu Jahnavi ${ }^{\mathrm{a}}$, and Kattamanchi V.Kranthi Kumar ${ }^{\mathrm{b}}$ \\ ${ }^{a}$ Assistant Professor,Gokaraju Rangaraju Institute of Engineering and Technology, Hyderabad 500090, India \\ bational Institute of Technology, Warangal 506004, India
}

\begin{abstract}
To reduce the swell pressures in expansive soils usually granular piles are used, but due to lack of availability there is need of a material which is highly compressible and economical also. EPS Geofoams are obtained by expanding the polystyrene polymer which is a by-product obtained from the petroleum industry. As the drainability of the Geofoam is very less a layer of Geocomposite is surrounded over the geofoam especially for allowing the drainage. So, the mechanism involved in the study is that whenever a saturated soil swells in vertical direction this Geofoam will give room to accommodate the lateral swell which leads to reduction in the vertical heave and Geocomposite will dissipate the excess pore pressure generated during swelling of the soil. In the present study an attempt was made to predict the performance of EPS Geofoam and Geocomposite in reducing the soil heave due to constant infiltration. A two dimensional (2D) numerical model was developed using GEOSTUDIO 2012 to predict the behaviour of the swelling soil due to the inclusion of Geofoams as well as stone columns. Generally coupled and uncoupled analysis are performed to study the behaviour of the swelling soil but as the uncoupled analysis is more advantageous than coupled analysis it is performed in the present study.
\end{abstract}

\section{Introduction}

Expansive soils predominantly present in arid and semiarid regions, covers all the parts of the world. Expansive soils encounter an adverse volume change (swelling or shrinkage) due to water content fluctuations. These soils swell when water comes in contact with it and shrinks when water drains out. The phenomenon leads to the cracking of lightly loaded structures built on them. In order to control the distress problems posed by expansive soils, various techniques have been evolved. Soil stabilization is one of the most widely followed techniques to provide desired characteristics for soft clays and expansive soils. In the view of physical stabilization Geosynthetics inclusion has been widely used to decrease the swelling potential in expansive soils. One of the common inclusion materials are EPS Geofoam products because they perform better among other inclusion materials due to their high compressible nature, desirable properties and durability in the applications related to geotechnical engineering. The use of EPS Geofoam as horizontal or vertical compressible inclusion in problematic expansive soil is reported by very few researchers. Several scientists tried to understand the swelling behaviour of expansive soil [13]. Rawas, Hago and Sarmi tried to study the usage of different materials like Lime, Cement and Artificial Pozzolona and on comparative basis Lime is found to be superior in reducing swelling behaviour. Ikizler (2009). conducted laboratory tests in steel testing box under constant volume, using EPS Geofoam as a vertical compressible inclusion material against rigid walls to decrease lateral swell pressure in expansive soil [5]. According to Shelke and Murthy the reduction in the swell pressure and the decrease in the percent swell were mainly due to the higher compressibility behavior of EPS Geofoam[6]. Laboratory study is conducted to investigate the use of EPS in the form of Geofoam column inclusion which reduce the swell pressure and swelling potential of expansive soil by Selvakumar and Soundara and further it is observed that rate of swelling is more with Geofoam inclusion because of these probable two reasons: presence of minute gap between Geofoam column and soil which allows the free flow of water and due to water absorption capability of EPS[7]. Sayed, Tamer and Ahmed concluded that numerical modelling Geofoam inclusions to study expansive soils yield good results and also by increasing the thickness of Geofoam significant heave reduction was observed[8]. Recently, Deng and Yang reported that the performance of EPS Geofoam is better in reducing the swell pressure compared to that of sand and cohesive non swelling soil [9]. Due to the multi-functional nature EPS Geofoam can also act as thermal insulator additionally while serving the purpose of compressible inclusion [10]. Other researchers have also worked on using EPS Geofoam for expansive soils [11-12]. Vanapalli has taken up the challenge of modelling heave of expansive soils [13-14]. Some extensive works gave the understanding of the modelling of heave [15] and to replicate the coupled and

\footnotetext{
* Corresponding author: jahnavithentu@gmail.com (Thentu Jahnavi)
} 
uncoupled modelling [16]. Few research works can be referred to understand the EPS Geofoam [17]. But comparative studies of reducing the heave is not much observed in the literature. This paper explores the comparison of EPS Geofoam and Stone columns in heave reduction.

\section{Methodology}

Soil geometry is selected and then Geofoams of suitable diameter are installed with appropriate spacing below the flexible cover. Similarly stone columns with same diameter and spacing as that of Geofoams are placed in the soil for determining the efficacy of both the improvements.

Generally expansive soils will swell when water comes in contact with it and they shrink when water leaves the soil mass. When a constant infiltration is applied to the soil mass progressive swelling of the soil will takes place (without shrinkage) and the infiltration rate applied to the soil mass should not exceed the saturated hydraulic conductivity of the soil. But in case of cyclic infiltration the rate of infiltration applied is fixed for certain period so that soil swells when infiltration is taking place (in the specified period) and its shrinks when the infiltration is not assigned. The saturated hydraulic conductivity of the soil taken is 5.7 e- 6 and the infiltration rate is fixed at 5.7e-7.

As the construction phase continues for some period loading should also be given such that it increases in a staged manner. Using step data function this field condition can be replicated in Geostudio[18,19] in which incremental loading of $50 \mathrm{kPa}$ is assigned for every 30 days period and continued up to 300 days.

On combining the above two boundary conditions it will lead to following four combinations

- Constant load and constant infiltration

- Constant load and cyclic infiltration

- Step loading and constant infiltration

- Step loading and cyclic infiltration

The performance of stone columns and EPS Geofoams for the above four combinations has to be determined so that efficacy of these two ground improvements especially in cyclic swelling and shrinkage can be known.

\subsection{Materials}

The residual soil is taken from Bac Ai district, Ninh Thuan province, Central Vietnam and properties mentioned in Table 1. Heaving in this soil occurs due to presence of montmorillonite. One of the major challenges in expansive soils is to estimate the variation of heave during cyclic swelling and shrinkage. To reduce the heave EPS Geofoam is used which allows lateral expansion due to its cushioning effect so that vertical heave is reduced. Generally, to study the behavior of the expansive soils one can perform either coupled or uncoupled analysis in Geostudio. Uncoupled analysis is much more compatible with insitu conditions than coupled analysis. In the uncoupled analysis, rainfall- induced pore-water pressure change was simulated using $\mathrm{SEEP} / \mathrm{W}$ alone and the resulting pore-water pressure change was employed in SIGMA/W for the volume change analysis.

Table 1. Soil properties

\begin{tabular}{|l|l|}
\hline Property & Values \\
\hline Unit weight & $18 \mathrm{kN} / \mathrm{m}^{3}$ \\
\hline Poisson ratio & 0.3 \\
\hline Saturated elastic modulus & $3000 \mathrm{kN} / \mathrm{m}^{2}$ \\
\hline $\begin{array}{l}\text { Saturated hydraulic } \\
\text { conductivity }\end{array}$ & $5.7 \mathrm{e}-7 \mathrm{~m} / \mathrm{s}$ \\
\hline Activation PWP & $400 \mathrm{kPa}$ \\
\hline Coefficient of volume change & $0.00062 \mathrm{~m}^{2} / \mathrm{kPa}$ \\
\hline
\end{tabular}

\subsection{Geometry}

Soil is taken whose properties as mentioned in previous section. A flexible cover is laid at middle one third length of the soil placed. First and last one third length of the soil is left free over which infiltration at the rate of $5.7 \mathrm{e}-7 \mathrm{~m} / \mathrm{s}$ is assigned. EPS Geofoams (Table 2) are placed under the flexible cover with a diameter of $0.5 \mathrm{~m}$ and centre to centre spacing of $1.0 \mathrm{~m}$. In order to allow the drainage a Geocomposite (Table 3) (a layer of Geonet placed between two Geotextiles) is surrounded over the Geofoams so that time for heave reduction can be accelerated.

Table 2. EPS Geofoam properties

\begin{tabular}{|l|l|}
\hline Parameter & Value \\
\hline Material category & Effective drained \\
\hline Material model & Linear elastic \\
\hline Effective E modulus & $7800 \mathrm{kPa}$ \\
\hline Poisson ratio & 0.17 \\
\hline Unit weight & $0.3 \mathrm{kN} / \mathrm{m}^{3}$ \\
\hline
\end{tabular}

A cushion of sand bed with a thickness of $0.3 \mathrm{~m}$ is placed over the EPS Geofoam columns in order to distribute the stresses uniformly and also to provide the drainage path.

Table 3. Properties of Geocomposite

\begin{tabular}{|l|l|}
\hline Parameter & Value \\
\hline Material model & Interface \\
\hline Tangential conductivity & $1.846 \mathrm{E}-6 \mathrm{~m} / \mathrm{s}$ \\
\hline Normal conductivity & $0.0923 \mathrm{~m} / \mathrm{s}$ \\
\hline
\end{tabular}

Similarly stone columns (properties mentioned in Table 4)are also placed in the same way as that of Geofoams having same diameter and spacing in order to compare the performances of these two improvements in reducing the heave. The following Figure 1 shows the soil geometry modeled in Geostudio. 
Table 4. Stone column properties

\begin{tabular}{|l|l|}
\hline Parameter & Value \\
\hline Material category & Effective drained \\
\hline Material model & Linear elastic \\
\hline Effective E modulus & $25000 \mathrm{kPa}$ \\
\hline Poisson ratio & 0.35 \\
\hline Unit weight & $19 \mathrm{kN} / \mathrm{m}^{3}$ \\
\hline
\end{tabular}

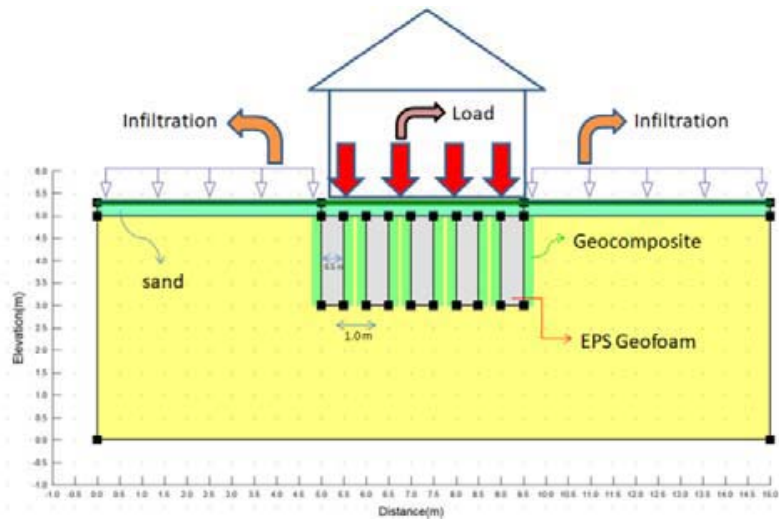

Fig. 1. Soil geometry

\subsection{Boundary conditions}

Generally boundary conditions are to simulate the field condition in the numerical model. Depending upon the site conditions the following types of boundary conditions are used in SEEP/W and SIGMA/W.

$\mathrm{BC} 1$ "Fixed $\mathrm{X} \&$ \& Fixed $\mathrm{Y}$ at bottom boundary" the bottom boundary is not allowed (fixed) to move in horizontal as well as vertical direction.

$\mathrm{BC} 2$ "Fixed $\mathrm{X}$ at side boundaries" the side boundaries are allowed to move in vertical direction but not in horizontal direction.

BC3 "Initial suction at bottom boundary" generally the initial suction of $-400 \mathrm{kPa}$ is given in terms of pressure head (i.e.,-40.28m) but instead of defining it in terms of pressure head, it is assigned in terms of Activation Pore water pressure (PWP) of $-400 \mathrm{kPa}$ in soil properties.

BC4 "Constant Infiltration" the rate of infiltration is fixed at $5.7 \mathrm{e}-6 \mathrm{~m} / \mathrm{s}$ which is greater than the hydraulic conductivity of soil $(\mathrm{k}=5.7 \mathrm{e}-7 \mathrm{~m} / \mathrm{s})$ for a period of 300 days. It is defined as unit flux (q) in transient seepage analysis (SEEP/W) and as a constant function with an assigned value of $5.7 \mathrm{e}-6 \mathrm{~m} / \mathrm{s}$.

BC5 "cyclic Infiltration" the infiltration rate of 5.7e-5 $\mathrm{m} / \mathrm{s}$ is assigned to the ground surface for alternate cycles of 30 days around the structure over 300 days. It is defined as a boundary function in transient seepage analysis (SEEP/W) with water unit flux vs time as the parameters and is assigned to the model as a step data point function with the following values shown in the table.
BC6 "constant loading" A constant load of $50 \mathrm{kPa}$ is applied on te flexible cover for a period of 300 days. It is defined as a constant function in volume change analysis (SIGMA/W) with Normal boundary stress vs time as the parameters and is assigned to the model as a step data point function with the following values shown in the table

BC7 "Step loading" the load is applied in the increments of $50 \mathrm{kPa}$ for every 30 days and is continued up to $300 \mathrm{kPa}$ for 300 days. It is defined as a Normal function in volume change analysis (SIGMA/W) with Normal boundary stress vs time as the parameters and is assigned to the model as a step data point function with the following values shown in the table.

BC8 "potential seepage face review" this boundary condition is defined in transient seepage analysis $(\mathrm{SEEP} / \mathrm{W})$ which helps to avoid ponding of water on the surface of the soil. If the soil reaches its field capacities then excess infiltration will runoff from the surface without increasing the water head above the soil.

\section{Results and discussions}

After performing the uncoupled analysis the heaving of the soil is observed after placing EPS Geofoams and stone columns at Edge and Center of the flexible cover for the following two combinations of boundary conditions namely

- $\quad$ Step loading and constant infiltration

- Step loading and cyclic infiltration

Initially the rate at which soil heaves has to be determined before placing the Geofoam columns and stone columns then the reduction in the soil heave after these ground improvements have to be determined so as to assess the performance of these two improvements in reducing the heave. Soil is observed to have a heave of $10.4 \mathrm{~cm}$ at edge and $9.94 \mathrm{~cm}$ at center under step loading of constant infiltration case and a heave of $10.09 \mathrm{~cm}$ at edge and $9.61 \mathrm{~cm}$ at center under step loading of cyclic infiltration case.

\subsection{Step loading and constant infiltration at edge}

Amount of heave reduced using stone columns and EPS Geocomposite at edge is nearly same and because of compressible behaviour of Geofoam it compresses more than stone column after 300 days of constant infiltration and step loading. The change can be seen Fig 3.1 


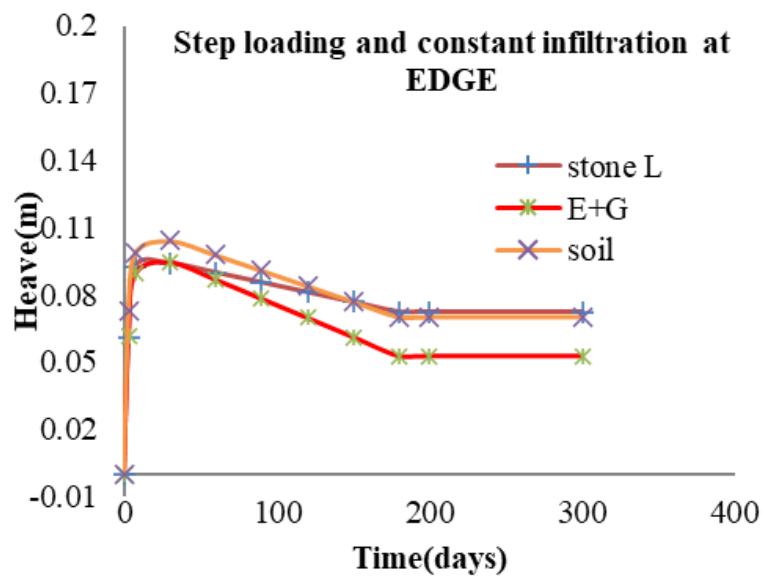

Fig. 3.1. Heave vs Time graph at Edge(constant infiltration)

\subsection{Step loading and constant infiltration at center}

EPS Geocomposite performs better than stone columns at centre because the rate of saturation at centre is less compared to edge which leads to progressive swelling and due to the flexible nature of Geofoam it accommodates large amount of lateral swell thereby heave is reduced. And can be observes in fig 3.2

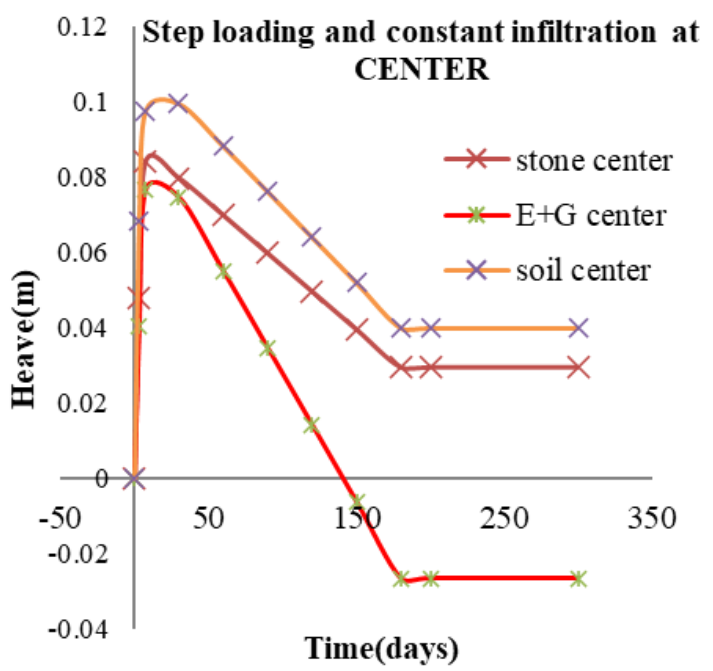

Fig. 3.2. Heave vs Time graph at Centre (constant infiltration)

\subsection{Step loading and cyclic infiltration at edge}

The EPS Geofoam and Geocomposite performs better than stone columns with cyclic infiltration at Edge, further as the resultant load passes through the centre it compresses more than that of stone columns. This comparison can be acknowledged from Fig 3.3

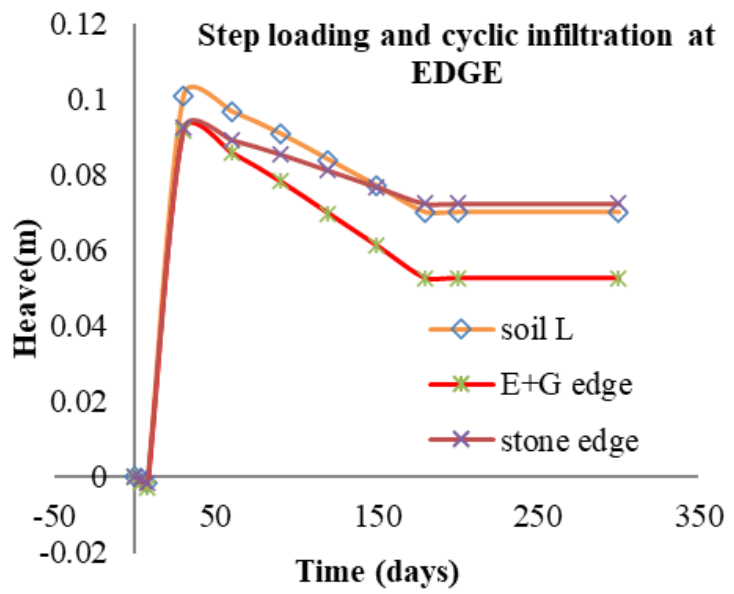

Fig. 3.3. Heave vs Time graph at Edge(cyclic infiltration)

\subsection{Step loading and cyclic infiltration at center}

The performance of EPS Geofoam and Geocomposite with cyclic infiltration is enhanced as its stress-strain behaviour is linear up to $5 \%$ of strains so that it undergoes large amounts of strains linearly for consecutive cycles of swelling and shrinkage.

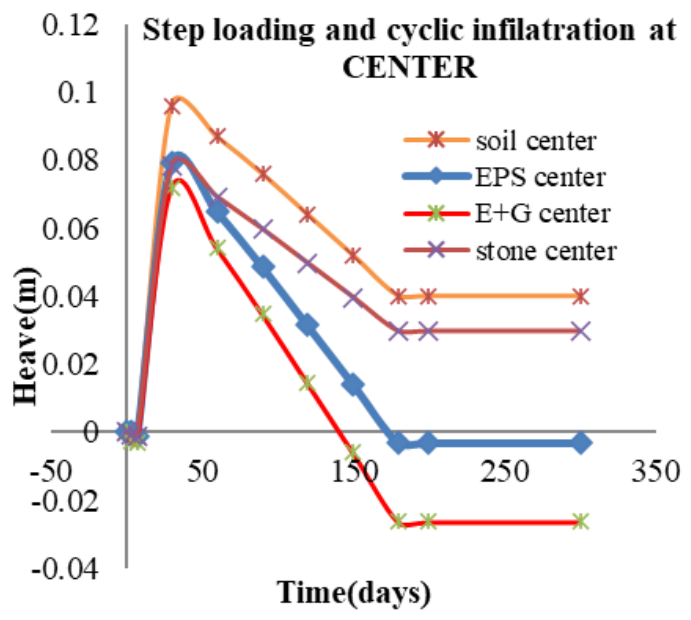

Fig. 3.4. Heave vs Time graph at Centre (cyclic infiltration)

\section{Conclusions}

In the case of constant infiltration under step loading the EPS Geofoam combined with Geocomposite gave greatest reduction in heave at edge followed by stone columns and EPS Geofoam alone.

At the center the order of reduction of heave is same as that of edge except there was bigger difference in EPS Geofoam added by Geocomposite and Stone Columns under step loading of constant infiltration case.

For cyclic infiltration under step loading same as above EPS Geofoam with Geocomposite gave best percentage of reduction of heave at center and also at the edge. But there is a wide gap in reduction of heave for EPS 
Geofoam with Geocomposite and Stone Columns at the center.

\section{References}

1. F.H.Chen and G.S.Ma, Proceedings of 6th International Conference on Expansive soils, New Delhi (1987)

2. A.A.Basma, Geotechnical Testing Journal 16, 542-549 (1993)

3. A.S.Al-Homoud, A.A.Basma and A.I..H.Malkavi, Journal of geotechical Engineering, 525-565 (1995)

4. A.Al-Rawas, A.W.Hago and H.Al.-Sarmi, Building and Enivronment 40, 681-687 (2005)

5. S.B.Ikizler, M.Aytekin and M.Velki, Geosynth.Int 16, 216-221 (2009)

6. A.P.Shelke and D.S.Murthy, Paper No. H-128, Kochi (2011)

7. S.Selvakumar and B.Soundara, Geotext. Geomembr 47, 1-11,(2018)

8. M.Sayed, M.Tamer and M.Ahmed, IOSR-JMCE 17, 41-49 (2020)

9. A.Deng and X.Yang, Int. J. Geomec 10, no. 6 (2020)

10. J.S.Horvath, Geotext. Geomembr 15, 77-120, (1997)

11. T.D.Stark, S.F.Barlett and D.Arellano, The EPS Industry Alliance 1298, 36 (2012)

12. M.Aytekin, Geotext. Geomembr 15, 133-146 (1997)

13. S.K.Vanapalli and L.LU, Int. J. Geotech. Eng 6, 15-4 (2012)

14. H.H.Adem and S.K.Vanapalli, Int. J. Geotech. Eng 7, 199-204 (2013)

15. H.Q.Vu and D.G.Fredlund, Can. Geotech. J 43, 1249-1272 ( 2006)

16. V.Hung and S.K.Saskatoon, University of Saskatchewan, Canada ( 2003)

17. A.F.Elragi, Syracuse, NY, (2000)

18. Stress deformation modeling with SIGMA/W , GEO-SLOPE International limited. (2012)

19. Seepage modeling with SEEP/W 2012, GEOSLOPE International limited. (2012) 